\title{
A prospective study of microscope-integrated intraoperative fluorescein videoangiography during arteriovenous malformation surgery: preliminary results
}

\author{
Brandon C. Lane, M.D., and Aaron A. Cohen-Gadol, M.D., M.Sc. \\ Goodman Campbell Brain and Spine, Indiana University Department of Neurological Surgery, \\ Indianapolis, Indiana
}

\begin{abstract}
Object. The authors report on the use of a recently developed microscope-integrated fluorescent module using low-dose intravenous fluorescein for videoangiography during arteriovenous malformation (AVM) surgery.

Methods. The authors analyzed the application of a low-dose intraoperative fluorescein in 4 consecutive patients undergoing AVM surgery. The ability to distinguish the associated vessels of the AVM from normal vessels and to assess the degree of AVM obliteration based on videoangiography of venous drainage was specifically analyzed.

Results. All 4 patients underwent fluorescein angiography without complication. In each case, videoangiography confirmed recognition of feeding arteries and draining veins through the operating oculars under the fluorescent mode. In one case involving a large frontal AVM, videoangiography demonstrated mainly cortical veins on the surface of the AVM and alerted the senior author to first tackle the feeding arteries in the interhemispheric space. While evaluating the flow within the different draining veins after most of the AVM was disconnected, videoangiography also prioritized the order for disconnection of large draining veins to allow mobilization the AVM and exposure of the remaining deep arterial feeders. In the other 3 cases, videoangiography allowed easy recognition of the angioarchitecture of the AVMs, estimated its cortical boundaries, and most importantly, assessed the flow within the draining veins before their disconnection.

Conclusions. The authors found fluorescein videoangiography to be a useful adjunct in resection of AVMs. This technology offers the unique ability to visualize fluorescent vessels and nonfluorescent tissues in near-natural colors simultaneously and permits microsurgical manipulation of relevant structures under the fluorescent mode. Largerscale studies are needed to establish its efficacy and wider applicability.

(http://thejns.org/doi/abs/10.3171/2013.11.FOCUS13483)
\end{abstract}

KEY WORDS • fluorescein $\quad \bullet \quad$ videoangiography $\quad \bullet \quad$ arteriovenous malformation
microsurgical resection

$\mathrm{T}$ IHE use of fluorescence imaging technologies in neurosurgery has been widely reported dating back to $1948 .{ }^{13}$ Although the first reports of fluorescence angiography to visualize cerebral vessels using fluorescein appeared in 1967, recent reports have focused on indocyanine green (ICG) due to the development of a practical microscope-integrated ICG-imaging infrared module. ${ }^{3}$ Indocyanine green fluorescence angiography has been a useful adjunct in aneurysm surgery, as it allows for timely and safe evaluation of large vessels, aneurysms, and small perforating arteries exposed at surgery. For these reasons, it has also been evaluated as an adjunct in the microsurgical treatment of arteriovenous malformations (AVMs). ${ }^{8}$ Takagi et al..$^{25}$ noted that ICG is easier to detect and characterized by a lower rate of adverse reactions than fluores-

\footnotetext{
Abbreviations used in this paper: AVM = arteriovenous malformation; DSA = digital subtraction angiography; ICG = indocyanine green.
}

cein. However, the recent development of a microscopeintegrated fluorescein videoangiogram module allows for administration of small amounts of fluorescein with the added ability to visualize the operative field under a realtime fluorescence mode. ${ }^{10,11,19,20}$ These new advancements offer easy intraoperative detection of fluorescein and an improved rate of adverse reactions, which, based on ophthalmological studies, are comparable to those of ICG. ${ }^{4,29}$

In this study, we report on the use of this newly developed microscope-integrated fluorescein videoangiogram module in the evaluation and treatment of AVMs. To our knowledge, this is the first report on the use of this technology for AVM surgery.

\section{Methods}

\section{Patient Population}

This study includes prospective data on 4 consecutive patients in whom AVM resection was performed using 


\section{B. C. Lane and A. A. Cohen-Gadol}

$75 \mathrm{mg}$ intravenous sodium fluorescein and the YELLOW 560 microscope-integrated module (Zeiss Meditec) as an intraoperative imaging adjunct. The patients' characteristics are summarized in Table 1 . The patients ( 2 male and 2 female) ranged in age 32 to 47 years (mean 37 years). The Indiana University Institutional Review Board reviewed and approved this study, and all patients provided consent before participation.

\section{Sodium Fluorescein Dye}

Sodium fluorescein has been used extensively in ophthalmological angiography of the retina. It is commercially available as a small organic molecule supplied in an aqueous solution with a $\mathrm{pH}$ of 8.0-9.8 and osmolality of $727-858 \mathrm{mOsm} / \mathrm{kg}$. Sodium fluorescein fluoresces with wavelengths of 520-530 nm in response to excitation with light at 465-490 nm wavelengths. In practice, this results in yellowish-green fluorescence that can be detected by videoangiography or by the observer's naked eye, at low and high intravenous doses, respectively.

Pharmacokinetically, fluorescein distributes well into the interstitial space, with an estimated volume of distribution of $0.5 \mathrm{~L} / \mathrm{kg}$. Approximately 20-30 seconds after a bolus peripheral venous administration, fluorescein can be observed in the cerebral circulation.

Fluorescein metabolism is primarily achieved through conversion to fluorescein monoglucuronide in the liver. This process is rapid, with approximately $80 \%$ conversion within 1 hour of injection. Furthermore, fluorescein is excreted via renal clearance at a rate of $1.75 \mathrm{ml} / \mathrm{min} / \mathrm{kg}$. Systemic clearance ranges from 48 to 72 hours in doses of 500 $\mathrm{mg}$ used in ophthalmological studies. Fluorescein contraindications only include those with known hypersensitivity to sodium fluorescein or other ingredients in the clinical solution (http://dailymed.nlm.nih.gov/dailymed/lookup.cfm? setid=ebb3883c-71f6-4fd0-a7e6-0ba8e1136dd9).

Due to its popularity in ophthalmological angiography, fluorescein's side effect profile has been well characterized. Yanuzzi et al. ${ }^{29}$ performed a large complication survey in 1984 that included 2434 opthalmologists and more than 220,000 angiograms. Side effects were categorized as mild, moderate, or severe. Mild and moderate reactions were classified both as transient in effect and with no subsequent sequelae or threat to patient safety. Specifically, mild reactions included nausea, vomiting, sneezing, pruritis, extravasation, and inadvertent arterial injection. Approximately $87 \%$ of survey respondents indicated a frequency of mild reactions of less than 5\%. Moderate reactions included urticaria, syncope, other skin eruptions, thrombophlebitis, pyrexia, local tissue necrosis, and nerve palsy. These were reported with a frequency rate of 1 per 63 cases. Severe reactions were defined as those involving prolonged effects requiring intense treatment and resulting in variable recovery. These included laryngeal edema, bronchospasm, anaphylaxis, circulatory shock, myocardial infarction, cardiac arrest, and tonic-clonic seizure. These reactions were reported at a rate of 1 per 1900 cases. One death was reported in the study (rate of 1 per 222,000 cases). ${ }^{29}$ High-dose fluorescein $(20 \mathrm{mg} / \mathrm{kg})$ has been used in neurosurgery for fluorescence-guided glioma resection, and there have been 2 reports of anaphylaxis

\section{TABLE 1: Summary of patient characteristics}

\begin{tabular}{cccccc}
\hline $\begin{array}{c}\text { Age } \\
\text { Case } \\
\text { No. }\end{array}$ & $\begin{array}{c}\text { (yrs), } \\
\text { Sex }\end{array}$ & AVM Location & $\begin{array}{c}\text { AVM } \\
\text { Size }\end{array}$ & $\begin{array}{c}\text { Preop } \\
\text { Embolization }\end{array}$ & Presentation \\
\hline 1 & $35, \mathrm{M}$ & It frontal & $4 \mathrm{~cm}$ & yes & seizures \\
2 & $32, \mathrm{~F}$ & It parietal & $3 \mathrm{~cm}$ & yes & $\begin{array}{l}\text { headache } \\
\text { severe } \\
3\end{array}$ \\
$47, \mathrm{~F}$ & rt posterior frontal & $5 \mathrm{~cm}$ & yes & $\begin{array}{c}\text { headache } \\
\text { seizures }\end{array}$ \\
\hline
\end{tabular}

with this large dose. ${ }^{1,26}$ It is important to note that these studies reported only on the use of high-dose fluorescein.

Fluorescein does not cross the intact blood-brain barrier and remains largely intravascular. Extravascular fluorescein leakage is due to loss of integrity of the bloodbrain barrier., ${ }^{710}$ Dural vessels stain as a result of this phenomenon and can interfere with imaging of neighboring structures. Large vessels tend to stain with repeated use..$^{18}$ This is likely due to accumulation of fluorescein within the vessel wall; we have not observed this phenomenon with smaller vessels.

\section{Microscope-Integrated Fluorescein Module}

We performed intraoperative videoangiography using an OPMI PENTERO 900 operating microscope (Zeiss Meditec), which is equipped with the YELLOW 560 integrated fluorescence module..$^{10,11,19,20}$ This module utilizes stimulus light between 400 and $500 \mathrm{~nm}$ and detects wavelengths in the range of 540 to $690 \mathrm{~nm}$ for display of fluorescence. These specifications match those of sodium fluorescein fluorescence. This module has recently been integrated into the surgical microscope to allow the surgeon the ability to switch between stimulus light and white-light illumination by merely pressing a button. The optics of this module allow for visualization of nonfluorescent structures in nearly natural hue under fluorescent mode imaging. Furthermore, the module allows for highdefinition digital recording of the operative field and fluorescent structures. This combination maximizes tissue details and optimizes microsurgical work while imaging in fluorescent mode.

The INFRARED 800 fluorescence camera, used for ICG imaging, separates emission and excitation light. Therefore, only fluorescent areas are visible in standard definition quality, but nonfluorescent areas appear black. The INFRARED 800 is designed for an excitation range of 700-780 $\mathrm{nm}$ and emission detection in the range of 820-900 $\mathrm{nm}$. The ICG signal emission cannot be seen through the operating oculars and must be processed and displayed on a monitor. This technology does not allow for visualization of operative field under the fluorescent mode. The phenomenon of chromatic aberration significantly degrades image quality under high magnification of the operating microscope.

\section{Technique for Fluorescence Angiography}

After craniotomy and exposure of the AVM, a 75-mg 
bolus of sodium fluorescein (Akorn, Inc.) was administered through a peripheral intravenous line, and the fluorescent module was used for imaging. Fluorescent signal was apparent through the operating oculars after 10-15 seconds within the cortical vessels. This small dose is $15 \%$ of the dose previously used for neoplastic and vascular applications..$^{3,5,9,15,22,24}$ We chose this dose based on our previous experience. We had decreased fluorescein dosing gradually from $200 \mathrm{mg}$ in 25 increments for the previous 10 patients who harbored brain aneurysms. Based on this experience, we concluded that $75 \mathrm{mg}$ was the lowest dosage that provided good fluorescent vascular imaging.

We used the following steps to perform 2-3 intraoperative videoangiograms for each AVM. The first videoangiogram was completed before AVM resection and evaluated normal cortical versus AVM feeding arteries (angioarchitecture). It also delineated the estimated cortical boundaries of the AVMs.

After most of the feeding arteries were disconnected, the status of the draining veins was assessed before their disconnection, using additional videoangiograms. More specifically, 1-2 additional injections (the number being based on the number of large draining veins present for the AVM) of fluorescein (75 $\mathrm{mg}$ dosing repeated) were used to assess the significance of draining veins for the partially disconnected AVM. The large draining veins with slowest flow as demonstrated through videoangiography were sacrificed first. The disconnection of this cortical vein allowed further mobilization of the AVM and facilitated further AVM disconnection until the AVM was completely excised.

\section{Results}

All 4 patients underwent fluorescein angiography with no complication. In each case, videoangiography allowed a better understanding of the AVM's angioarchitecture and recognition of feeding arteries and draining veins. In one case involving a large frontal AVM, videoangiography demonstrated mainly cortical veins on the surface of the AVM and alerted the senior author (A.A.C.-G.) to first tackle the feeding arteries in the interhemispheric space. Videoangiography also prioritized the order for disconnection of large draining veins to allow mobilization of the AVM and exposure of the deep arterial feeding vessels.

In the other 3 cases, videoangiography readily allowed recognition of the AVM angioarchitecture and estimation of its cortical boundaries and, most importantly, assessed the flow within the draining veins before their disconnection. The ability to visualize the above fluorescence information through the operating oculars allowed the operator to readily appreciate the significance of this information in relation to the surrounding normal neurovascular structures. Ultimately, assessment of flow within the draining veins to prioritize their disconnection was the most important contribution of videoangiography. Postresection videoangiography was not performed as potential small deep residual AVMs are often not in the field of view of the microscope due to coverage by the surrounding cortex and white matter. Only postresection intraoperative arteriography was used to confirm a complete excision of the AVM.

\section{Illustrative Cases}

\section{Case 1}

A 35-year-old man presented after a seizure and was found to harbor a left frontal 4-cm AVM. Following embolization, he underwent microsurgical resection. After a frontal craniotomy and opening of the dura (Fig. 1A), fluorescein videoangiography revealed the cortical surface of the AVM. Based on this imaging, the surface cortical vessels associated with the AVM were determined to be predominantly draining veins (Fig. 1B). Although our initial plan was to disconnect the surface arterial feeders and then tackle the interhemispheric feeders originating from anterior cerebral arteries, we changed our plan based on fluorescein angiography information and first pursued the disconnection of interhemispheric feeders.

Following disconnection of the majority of superficial feeders, including the interhemispheric ones, fluorescein videoangiography was performed again to assess the flow status within the 2 draining veins in order to determine which vein could most safely be sacrificed to allow mobilization of the AVM and handling of deeper white matter feeders. This second fluorescein videoangiogram showed that the flow within the anterior vein was less that that in the posterior one (Fig. 1C), and therefore the former was disconnected, allowing the AVM to be mobilized posteriorly for its final excision.

\section{Case 2}

A 32-year-old woman presented with intractable headaches and was diagnosed with a $3-\mathrm{cm}$ left posterior parietal AVM. Following its embolization, the AVM was exposed through a parietal craniotomy (Fig. 2A). The initial videoangiogram demonstrated the angioarchitecture of the AVM (Fig. 2B). Following disconnection of the superficial feeders, another videoangiogram was performed (Fig. 2C); this revealed minimal flow within the parasagittal vein, which was disconnected to mobilize the AVM and allow for its complete excision.

\section{Discussion}

Fluorescence angiography is a recent development that uses both fluorescein and ICG as fluorophores to image cerebral vessels..$^{5,16,17,21,23,28}$ Fluorescein and ICG carry many of the same advantages and disadvantages. Both are easy to administer, inexpensive, and require no extra equipment or personnel. Fluorescein and ICG are equally effective in illuminating AVM vessels, including cortical feeding arteries and draining veins, as compared with digital subtraction angiography (DSA). Unfortunately, both ICG and fluorescein are only useful at visualizing vessels within the field of view of the microscope. This fact is a major limitation for confirmation of complete AVM resection, and therefore DSA remains the gold-standard technique for this purpose.

Although ICG and fluorescein have many similarities, they are characterized by unique chemical properties, 


\section{B. C. Lane and A. A. Cohen-Gadol}
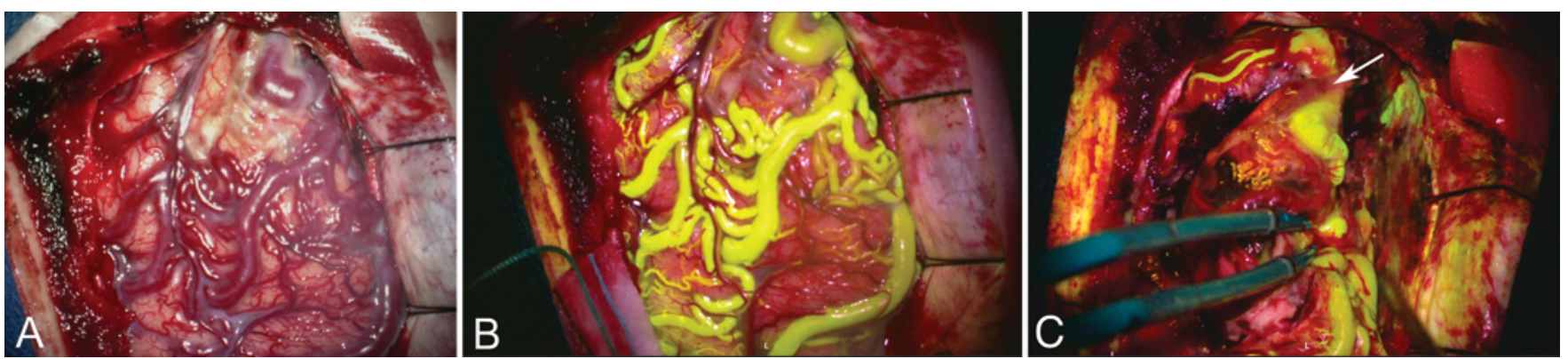

FIG. 1. Case 1. A 35-year-old man presented after a seizure and was found to harbor a left frontal 4-cm AVM. Following embolization, he underwent microsurgical resection. The AVM was exposed through a frontal craniotomy (A). The initial videoangiogram (B) demonstrated that the surface cortical vessels associated with the AVM were predominantly draining veins. This finding led the authors to first pursue disconnection of the interhemispheric feeders from the anterior cerebral arteries. Following disconnection of the majority of superficial feeders, including the interhemispheric ones, the second fluorescein videoangiogram (C) demonstrated that the flow within the anterior vein was less than that through the posterior one (note the area of minimal flow within the former marked with an arrow), and therefore the anterior vein was disconnected, allowing the AVM to be mobilized posteriorly for its final excision.

which confer distinct advantages and disadvantages. The combination of fluorescein and the YELLOW 560 module allows the surgeon to evaluate the surgical field in real time while looking through the microscope oculars under the fluorescent mode. This is possible since the emission of fluorescein falls within the visible electromagnetic spectrum, allowing for visualization of nonfluorescent structures in near-natural colors. This phenomenon allows the surgeon to mobilize and manipulate structures and more readily assess the fluorescent signal in relation to the surrounding cerebrovascular structures. As previously noted, repeated administration of fluorescein tends to stain the vessel walls in large caliber vasculature. ${ }^{18} \mathrm{We}$ did not observe this effect using the smaller dosing of fluorescein for our repeated injections for flow assessment within the draining veins.

Indocyanine green has been studied by multiple groups, and has been noted to easily provide relevant information integrated into a separate monitor. ${ }^{2,6,8,14,25}$ Major reported advantages of ICG include its rapid clearance and therefore its application for multiple injections. In addition, the FLOW 800 module allows objective timedependent assessment of intraoperative blood flow during removal of AVMs. ${ }^{2,6,14}$ Unfortunately, ICG imaging using the INFRARED 800 module separates fluorescent and nonfluorescent signals, whereby only the fluorescent sig- nal is visible through a designated monitor and all other signals are muted to black. It has been our experience that this phenomenon prevents safe manipulation of structures in the operative field under the fluorescent-mode microscopy.

As fluorescence angiography with either fluorescein or ICG is insufficient to detect feeders or residual AVM beneath the brain parenchyma or outside the microscope field of view, DSA remains the ideal surgical adjunct to detect residual deep-seated AVM. However, DSA is also associated with a number of drawbacks, including associated morbidity, expense, increased operating time, need for additional resources and personnel, and added interpretation of study results, because the information is not integrated into the surgeon's viewing field. ${ }^{8}$ Some have advocated for the use of Doppler ultrasonography to detect vessels associated with deep lesions beneath the brain parenchyma, but this modality lacks high resolution and does not offer a suitable alternative. ${ }^{12,27}$

\section{Conclusions}

Fluorescein and ICG have complementary advantages and disadvantages as fluorescent agents, and the use of fluorescein may provide additional advantages in the surgical management of select AVMs. Fluorescein


FIG. 2. Case 2. A 32-year-old woman presented with intractable headaches and was found to harbor a 3-cm left posterior parietal AVM. Following its embolization, the AVM was exposed through a parietal craniotomy (A). The initial videoangiogram (B) demonstrated the angioarchitecture of the AVM as well as the normal and arterialized draining veins. Following disconnection of the superficial feeders, repeat videoangiography $(\mathbf{C})$ revealed minimal flow within the parasagittal vein. This vein was disconnected to mobilize the AVM and allow for its complete excision. Note the area of minimal flow within this vein marked with an arrow. 
videoangiography allows the surgeon to manipulate the surgical field under the fluorescent mode microscopy. We conclude that intraoperative fluorescein videoangiography can be potentially useful in the treatment of AVMs. This is a preliminary study, and larger studies are necessary to better understand the efficacy of and indications for this technology.

\section{Disclosure}

At the time this study was conducted and written, the authors reported no conflict of interest concerning the materials or methods used in the study or the findings specified in this paper. After this study was accepted for publication, Dr. Cohen-Gadol agreed to a consulting contract with Carl Zeiss Meditec. The compensation from this contract is donated entirely to a not-for-profit educational organization, The Neurosurgical Atlas.

Author contributions to the study and manuscript preparation include the following. Conception and design: both authors. Acquisition of data: both authors. Analysis and interpretation of data: both authors. Drafting the article: both authors. Critically revising the article: both authors. Reviewed submitted version of manuscript: both authors. Approved the final version of the manuscript on behalf of both authors: Cohen-Gadol.

\section{References}

1. Dilek O, Ihsan A, Tulay H: Anaphylactic reaction after fluorescein sodium administration during intracranial surgery. J Clin Neurosci 18:430-431, 2011

2. Faber F, Thon N, Fesl G, Rachinger W, Guckler R, Tonn JC, et al: Enhanced analysis of intracerebral arterioveneous malformations by the intraoperative use of analytical indocyanine green videoangiography: technical note. Acta Neurochir (Wien) 153:2181-2187, 2011

3. Feindel W, Yamamoto YL, Hodge CP: Intracarotid fluorescein angiography: a new method for examination of the epicerebral circulation in man. Can Med Assoc J 96:1-7, 1967

4. Hope-Ross M, Yannuzzi LA, Gragoudas ES, Guyer DR, Slakter JS, Sorenson JA, et al: Adverse reactions due to indocyanine green. Ophthalmology 101:529-533, 1994

5. Järpe S: Cortical fluorescein angiography in neurosurgery. Acta Neurol Scand 44:177-182, 1968

6. Kato Y, Jhawar SS, Oda J, Watabe T, Oguri D, Sano H, et al: Preliminary evaluation of the role of surgical microscope-integrated intraoperative FLOW 800 colored indocyanine fluorescence angiography in arteriovenous malformation surgery. Neurol India 59:829-832, 2011

7. Kawase T, Mizukami M, Araki G: Mechanisms of contrast enhancement in cerebral infarction: computerized tomography, regional cerebral blood flow, fluorescein angiography, and pathological study. Adv Neurol 30:149-158, 1981

8. Killory BD, Nakaji P, Gonzales LF, Ponce FA, Wait SD, Spetzler RF: Prospective evaluation of surgical microscope-integrated intraoperative near-infrared indocyanine green angiography during cerebral arteriovenous malformation surgery. Neurosurgery 65:456-462, 2009

9. Koc K, Anik I, Cabuk B, Ceylan S: Fluorescein sodium-guided surgery in glioblastoma multiforme: a prospective evaluation. Br J Neurosurg 22:99-103, 2008

10. Lane BC, Cohen-Gadol AA: Fluorescein fluorescence use in the management of intracranial neoplastic and vascular lesions: a review and report of a new technique. Curr Drug Discov Technol 10:160-169, 2013

11. Li Y, Rey-Dios R, Roberts DW, Valdés PA, Cohen-Gadol AA: Intraoperative fluorescence-guided resection of high-grade gliomas: a comparison of the present techniques and evolution of future strategies. World Neurosurg [epub ahead of print], 2013

12. Mathiesen T, Peredo I, Edner G, Kihlström L, Svensson M,
Ulfarsson E, et al: Neuronavigation for arteriovenous malformation surgery by intraoperative three-dimensional ultrasound angiography. Neurosurgery 60 (4 Suppl 2):345-351, 2007

13. Moore GE, Peyton WT, French LA, Walker WW: The clinical use of fluorescein in neurosurgery. The localization of brain tumors. J Neurosurg 5:392-398, 1948

14. Ng YP, King NK, Wan KR, Wang E, Ng I: Uses and limitations of indocyanine green videoangiography for flow analysis in arteriovenous malformation surgery. J Clin Neurosci 20: 224-232, 2013

15. Okuda T, Kataoka K, Taneda M: Metastatic brain tumor surgery using fluorescein sodium: technical note. Minim Invasive Neurosurg 50:382-384, 2007

16. Raabe A, Beck J, Gerlach R, Zimmermann M, Seifert V: Nearinfrared indocyanine green video angiography: a new method for intraoperative assessment of vascular flow. Neurosurgery 52:132-139, 2003

17. Raabe A, Nakaji P, Beck J, Kim LJ, Hsu FP, Kamerman JD, et al: Prospective evaluation of surgical microscope-integrated intraoperative near-infrared indocyanine green videoangiography during aneurysm surgery. J Neurosurg 103:982-989, 2005

18. Raabe A, Spetzler RF: Fluorescence angiography. J Neurosurg 108:429-430, 2008 (Letter)

19. Rey-Dios R, Cohen-Gadol AA: Intraoperative fluorescence for resection of hemangioblastomas. Acta Neurochir (Wien) 155:1287-1292, 2013

20. Rey-Dios R, Cohen-Gadol AA: Technical principles and neurosurgical applications of fluorescein fluorescence using a microscope-integrated fluorescence module. Acta Neurochir (Wien) 155:701-706, 2013

21. Russell RW, Simcock JP: A new technique for examining the leptomeningeal circulation. Lancet 2:942-943, 1966

22. Shinoda J, Yano H, Yoshimura S, Okumura A, Kaku Y, Iwama $\mathrm{T}$, et al: Fluorescence-guided resection of glioblastoma multiforme by using high-dose fluorescein sodium. Technical note. J Neurosurg 99:597-603, 2003

23. Snyder LA, Spetzler RF: Current indications for indocyanine green angiography. World Neurosurg 76:405-406, 2011

24. Suzuki K, Kodama N, Sasaki T, Matsumoto M, Ichikawa T, Munakata R, et al: Confirmation of blood flow in perforating arteries using fluorescein cerebral angiography during aneurysm surgery. J Neurosurg 107:68-73, 2007

25. Takagi Y, Sawamura K, Hashimoto N, Miyamoto S: Evaluation of serial intraoperative surgical microscope-integrated intraoperative near-infrared indocyanine green videoangiography in patients with cerebral arteriovenous malformations. Neurosurgery 70 (1 Suppl Operative):34-43, 2012

26. Tanahashi S, Lida H, Dohi S: An anaphylactoid reaction after administration of fluorescein sodium during neurosurgery. Anesth Analg 103:503-504, 2006 (Letter)

27. Woydt M, Perez J, Meixensberger J, Krone A, Soerensen N, Roosen K: Intra-operative colour-duplex-sonography in the surgical management of cerebral AV-malformations. Acta Neurochir (Wien) 140:689-698, 1998

28. Wrobel CJ, Meltzer H, Lamond R, Alksne JF: Intraoperative assessment of aneurysm clip placement by intravenous fluorescein angiography. Neurosurgery 35:970-973, 1994

29. Yannuzzi LA, Rohrer KT, Tindel LJ, Sobel RS, Costanza MA, Shields W, et al: Fluorescein angiography complication survey. Ophthalmology 93:611-617, 1986

Manuscript submitted October 16, 2013.

Accepted November 26, 2013.

Please include this information when citing this paper: DOI: 10.3171/2013.11.FOCUS13483.

Address correspondence to: Aaron A. Cohen-Gadol, M.D., M.Sc., Goodman Campbell Brain and Spine, Indiana University Department of Neurological Surgery, 355 W. 16th St., Ste. 5100, Indianapolis, IN 46202. email: acohenmd@gmail.com. 